\title{
Kinetic modelling of dumpsite leachate treatment using Musa sapientum peels as bio- sorbent
}

\author{
L Salami ${ }^{1,}{ }^{*}$, DO Olumuyiwa ${ }^{2}$, EA Alfred ${ }^{2}$ and OS Olakanmi ${ }^{2}$ \\ ${ }^{1}$ Environmental Engineering Research Unit, Department of Chemical Engineering, Lagos State University, Epe, Lagos \\ State, Nigeria. \\ 2 Department of Chemical Engineering, Lagos State University, Epe, Lagos State, Nigeria.
}

Global Journal of Engineering and Technology Advances, 2021, 09(02), 024-031

Publication history: Received on 14 August 2021; revised on 13 November 2021; accepted on 15 November 2021

Article DOI: https://doi.org/10.30574/gjeta.2021.9.2.0117

\begin{abstract}
Kinetics models are very vital to dumpsite operators and planners as they provide relevant information for effective treatment of leachates. The aim of this work is to model the kinetic process of treatment of Lagos dumpsite leachate using Musa sapientum peels as bio-sorbent with a view of establishing the kinetic parameters of the treatment process. Musa sapientum peels which were collected from Ayetoro market in Epe Local Government area of Lagos State were used to prepare the bio-sorbent. Kinetic process was carried out using $1 \mathrm{~g}$ of the prepared bio-sorbent in $100 \mathrm{ml}$ Lagos dumpsite leachate in different conical flasks and at various contacting time. The kinetic data obtained were fitted to different kinetics models. The kinetics models tested were Fractional power model, Lagregren pseudo first - order model, Pseudo second - order model, Kuo - Lotse kinetic model, Blanchard kinetic model and Elovich kinetic model. Other kinetics models considered were Sobkowsk - Czerwi kinetic model, Intraparticle diffusion (IPD) model, Behnajady - Modirshahla - Ghanbery (BMG) model and Diffusion - Chemisorption model. Coefficient of determination $\left(R^{2}\right)$ values and the expected nature of the plots of the models were used to screen the tested models. The results revealed that the Pseudo second - order kinetic model has the best $\mathrm{R}^{2}$ value of 0.99996 and the graph followed the expected nature of the plot hence it was adopted in this work. It was concluded that Pseudo second - order kinetic model can be used to navigate the treatment process of Lagos dumpsite using Musa sapientum peels as bio-sorbent.
\end{abstract}

Keywords: Bio-sorbent; Kinetic; Leachate; Modeling; Musa sapientum and treatment

\section{Introduction}

The poor management of solid wastes generated by human activities is really contributing immensely to the environmental problems. The operation of dumpsites instead of engineered landfill sites is a major practice in developing countries (Nigeria inclusive). The leachates generated from the dumpsites pollute our environment and as a result, the leachates need to be treated before discharging to the environment or water bodies. Leachates can be treated by the use of activated carbons produced from agricultural wastes such as banana peels, woods, coconut shell, orange peels, rice straw, soya cake, cactus leaves, beech leaves and moss [1].

Several researchers have used agricultural wastes in the treatment of wastewater and leachates [2 - 13]. Saima et al. (2008) [2] evaluated banana peels in the treatement of arsenic contaminated water. The evaluation revealed that banana peels have a very high potential for the removal of arsenic from groundwater. El - Nafaty et al. (2013) [3]studied the biosorption and kinetic of oil removal from polluted water using banana peels. The study showed that banana peels obeyed Pseudo second - order kinetic model in the removal of oil from polluted water. Deshmukh et al. (2017) [11] investigated the removal of cadmium from aqueous solution using banana peels as adsorbent. The investigation pointed

\footnotetext{
${ }^{*}$ Corresponding author: Salami L

Environmental Engineering Research Unit, Department of Chemical Engineering, Lagos State University, Epe, Lagos State, Nigeria. 
out that the adsorption capacity of cadmium on dried banana peels was $5.91 \mathrm{mg} / \mathrm{g}$. It was also shown that the experimental data fitted into second order kinetic model.

Olafedehan et al., (2018 [12] worked on the equilibrum, kinetic and thermodynamic studies of biosorption of zinc ions from industrial wastewater using derived composite bio-sorbent from walnut shell. The work showed that the removal efficiencies of $\mathrm{Zn}$ (11) ions were effective in the acidic range. The experimental data correlated well with Pseudo second - order kinetic model. Sumanik et al. (2019) [13] researched on the use of banana peels for removal of lead in leachate. The research revealed the banana peels adsorbent has a capacity of $23 \mathrm{mg} / \mathrm{g}$ and could be used for treatment of leachates. Therefore the aim of this work is to model the kinetic process of treatment of Lagos dumpsite leachate using Musa sapientum peels as bio-sorbent with a view of establishing the kinetic parameters of the treatment process which gives vital information for the design of the treatment process [14]

\section{Methodology}

\subsection{Preparation of Adsorbent}

Muse sapientum peels were collected from a market in Ayetoro located in Epe Local Government, Lagos State, Nigeria. The peels were washed with water to remove any unwanted materials. The peels sample were carbonised for a duration of $1 \mathrm{hr}$ in a furnace. The char product from the furnace was cooled with cold water after which it was tranferred into the oven for further drying at $110^{\circ} \mathrm{C}$. The activated carbon was impregnated with tetraoxosulphate (vi) $\left(\mathrm{H}_{2} \mathrm{SO} \mathrm{O}_{4}\right)(10 \%$ by weight) and heated in the absence of air. The resultant moist paste was charged into the furnace followed by heating for $1 \mathrm{hr}$ at a temperature of $110^{\circ} \mathrm{C}$ until a constant weight of activated carbon was achieved. The chemical activation was done to remove the tar in the pores of the activated carbon. Distilled water was used to rinse the activated carbon thoroughly to remove the remaining $\mathrm{H}_{2} \mathrm{SO}_{4}$. The activated carbon was then dried with the aid of an oven at a temperature of $110^{\circ} \mathrm{C}$ for $3 \mathrm{hrs}$. A mortal was then used to crush the activated carbon to size of 100 mesh.

\subsection{Kinetic of Treatment Process}

$100 \mathrm{ml}$ of leachate collected from Soluos dumpsite in Lagos State, Nigeria, having a pH of 7.2 was measured into $250 \mathrm{ml}$ conical flasks containing $1 \mathrm{~g}$ each of the prepared bio-sorbent. The mixture was agitated with a shaker at $150 \mathrm{rpm}$ for 2 hrs after which it was left undisturbed for 20 mins and then filtered. The concentration of the total dissolved solid (TDS) in the filtrate was determined at $0 \leq t \leq 200$ mins using the standard methods prescribed by American Public Health Association (2005) [15] for the examination of water and wastewater. The percentage removal, $\theta$, adsorption capacity values at equilibrium, $q_{e}$, and time $t, q_{t}$, are determined using Equations 1 - 3 respectively (Olafadehan, 2021) [16].

$$
\begin{aligned}
& \theta=\left(\frac{c_{O}-c_{i}}{c_{o}}\right) \times 100 \\
& q_{e}=\left(\frac{c_{O}-c_{e}}{m}\right) v \\
& q_{t}=\left(\frac{c_{O}-c_{i}}{m}\right) v
\end{aligned}
$$

\section{Results and discussion}

\subsection{Effect of Contact Time}

The effect of contact time on the treatment of Lagos dumpsite leachate using Musa sapientum peels as bio-sorbent is shown in Figure 1 which depicts the graph of percentage removal against contact time. In Figure 1, the percentage removal of TDS increased as the contact time increased up to 150 mins when equilibrum was reached. At equilibrum, the percentage removal of TDS was 82.52 and there was no significant removal of TDS after the equilibrum has reached. Based on this observation, a contact time of 150 mins was adopted as the time the adsorbent reached saturation which was in line with previous studies (Gilbert at al., 2011 and Muibat et al., 2017). 


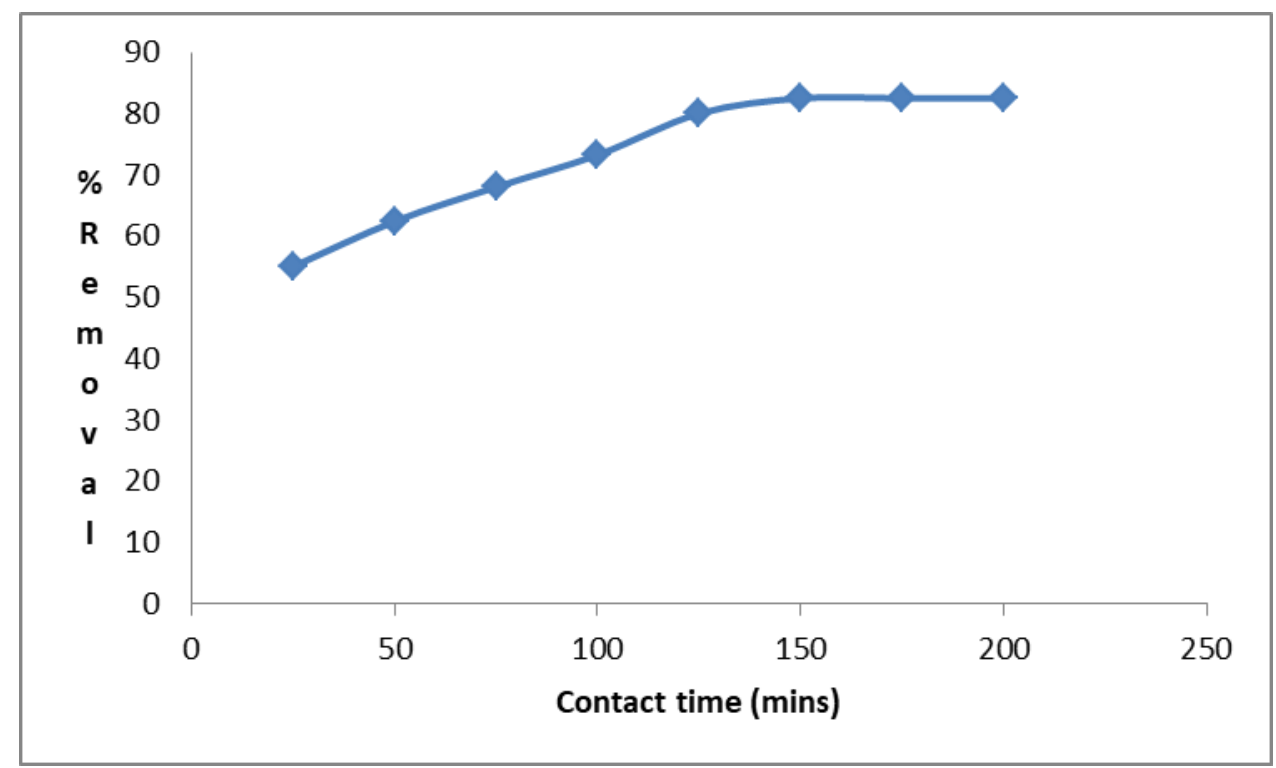

Figure 1A graph of \% removal against contact time at $\mathrm{pH}=7.2$, adsorbent dosage $=1 \mathrm{~g}$ and agitation speed $=150 \mathrm{rpm}$.

\subsection{Kinetic Modelling of Leachate Treatment}

Various kinetic models presented in Equations (4), (6), (8), (10), (12) and (14) [16]were used to test the kinetic data obtained during the kinetic process for the treatment of Lagos dumpsite leachate. Other kinetic models used to fit the experimantal data were shown in Equations (17), (19), (20) and (23) [16]. The Fractional power model which is of the form of Freundlich equation, indicates the adsorbate (or solute) uptake increases exponentially with time and it is given by:

$$
q_{t}=k_{F} t^{N}
$$

Where $k_{F}$ and $N$ are the fractional power kinetic model constant [=] mg/ $\left(\mathrm{g} \min ^{\mathrm{N}}\right)$. Taking the natural logarithm of Equation (4), it yields:

$$
\ln q_{t}=\ln k_{F}+N \ln t
$$

A plot of $\ln q_{t}$ against $\ln t$ was done to obtain the parameters inherent in Equation (5).

Lagergren Pseudo first - order kinetic model is presented in Equation (6).

$$
\frac{d q_{t}}{d t}=k_{1}\left(q_{e}-q_{t}\right)
$$

Where $k_{1}$ is the Lagergren Pseudo first - order rate constant [=] $\mathrm{min}^{-1}$. Integrating Equation (6), it gives:

$$
\ln \left(q_{e}-q_{t}\right)=\ln q_{e} k_{1} t
$$

A graph of $\ln \left(q_{e}-q_{t}\right)$ against $t$ was plotted to obtain the rate constant from the slope.

Pseudo second - order kinetic model is of the form shown in Equation (8)

$$
\frac{d q_{t}}{d t}=k_{2}\left(q_{e}-q_{t}\right)^{2}
$$


Where $k_{2}$ is the specific reaction rate constant for the pseudo second - order kinetics [=] g/ mg min). The integrated form of Equation (8) when linearized becomes:

$$
\frac{t}{q_{t}}=\frac{1}{k_{2} q_{e}^{2}}+\frac{t}{q_{e}}
$$

Hence a plot of $\frac{t}{q_{t}}$ against $t$ was carried out to determine the specific reaction rate constant for the pseudo second order kinetic.

Kuo - Lotse model which is also referred to as modified Freundlich kinetic equation is depicted in Equation (10).

$$
q_{t}=k_{m F} c_{e} t^{\frac{1}{\alpha_{m F}}}
$$

Where $k_{m F}$ is the apparent adsorption rate constant [=] $\frac{L}{g \min ^{\alpha_{m F}}}$ and $\alpha_{m F}$ is the Kuo - Lotse constant. Linearising Equation (10), it gives:

$$
\ln q_{t}=\ln \left(k_{m F} c_{e}\right)+\left(\frac{1}{\alpha_{m F}}\right) \ln t
$$

A plot of $\ln q_{\text {tagainst }} \ln t$ was carried out to determine the apparent adsorption rate constant and Kuo - Lotse constant. Blanchard kinetic model which is presented in Equation (12) was also applied to the kinetic data.

$$
q_{t}=\frac{k_{B} q_{e} t+\alpha_{B} q_{e}-1}{k_{B} t+\alpha_{B}}
$$

Where $k_{B}$ is the Blanchard kinetic rate constant $[=] \mathrm{g} /(\operatorname{mgmin})$ and $\alpha_{B}$ is the Blanchard model constant [=] g/mg. linearising Equation (12) when rearranged yields:

$$
\frac{1}{q_{e}-q_{t}}=k_{B} t-\alpha_{B}
$$

A plot of $\frac{1}{q_{e}-q_{t}}$ against $t$ was made to obtain the values of $k_{B}$ and $\alpha_{B}$ from the slope and intercept on vertical axis respectively.

Elovich kinetic model is of the form in Equation (14):

$$
\frac{d q_{t}}{d t}=\alpha \exp \left(-\beta q_{t}\right)
$$

Where $\alpha$ and $\beta$ are constants. Integrating Equation (14), we have:

$$
q_{t}=\frac{1}{\beta}[\ln (t+\phi)-\ln \phi]
$$


Where $\phi=\frac{1}{\alpha \beta}$. If $t \succ \succ \phi$, Equation (15) simplifies to:

$$
q_{t}=\frac{1}{\beta}(\alpha \beta)+\frac{1}{\beta} \ln t
$$

A linear plot of $q_{t}$ against $\ln t$ was done to check if $t \succ \succ \phi$ by determining the $\mathrm{R}^{2}$ value which should be greater than unity and this will eventually allow the determination of $\alpha[=] \mathrm{mg} /(\mathrm{gmin})$ and $\beta[=] \mathrm{g} / \mathrm{mg}$.

Sobkowsk - Czerwi kinetic model is shown in Equation (17) which when linearised gives Equation (18).

$$
\begin{aligned}
& q_{t}=\frac{q_{e} k_{s c} t}{1+k_{s c} t} \\
& \frac{q_{e}}{q_{t}}=\frac{1}{k_{s c}} t+1
\end{aligned}
$$

Where $k_{s c}$ is the Sobkowsk - Czerwi second order kinetic rate constant [=] $\min ^{-1}$. A plot of $\frac{q_{e}}{q_{t}}$ against $t$ was carried out to determine $k_{s c}$ from the slope while the value of intercept on the vertical axis which must be unity was used to check the fitness of the model.

Intraparticle diffusion (IPD) (or Weber and Morris) model is depicted in Equation (19).

$$
q t=k_{I P D} \sqrt{t}
$$

A plot of $q_{t}$ against $\sqrt{t}$ was made and $k_{I P D}$ which is the intraparticle diffusion rate constant [=] mg/(gmin $\left.{ }^{-1}\right)$ was determined from the slope and the intercept which must be at the origin was used to check the fitness of the model.

Behnajady - Modirshahla - Ghanbery (BMG) kinetic model is presented in Equation (20) which when linearized after rearrangement gives Equation (21).

$$
\begin{gathered}
q_{t}=q_{e}\left(1-\frac{t}{m+b t}\right) \\
\frac{t}{\left(1-\frac{q_{t}}{q_{e}}\right)}=m+b t
\end{gathered}
$$

A plot of $\frac{t}{\left(1-\frac{q_{t}}{q_{e}}\right)}$ against $t$ allowed for the determination of $b$ and $m$, which are the constants relating to the reaction kinetics and adsorption capacity, from slope and intercept on vertical axis respectively.

Diffusion - Chemisorption model in nonlinear form is shown in Equation (22) and the linear form is presented in Equation (23). 


$$
\begin{aligned}
& \frac{q_{e}^{2}}{\left(q_{e}-q_{t}\right)}=k_{D C \sqrt{t}}+q_{e} \\
& \frac{\sqrt{t}}{q_{t}}=\frac{1}{q_{e}} \sqrt{t}+\frac{1}{k_{D C}}
\end{aligned}
$$

Hence a plot of $\frac{\sqrt{t}}{q_{t}}$ against $\sqrt{t}$ was done to determine $\mathrm{k} D C[=] \mathrm{mg} /\left(\mathrm{gmin}^{0.5}\right)$ which is the Diffusion - Chemisorption parameter related to the rate of initial sorption, $k_{i}[=] \mathrm{mg} /(\mathrm{gmin})$.

The kinetic parameter and $\mathrm{R}^{2}$ values are presented in Table 1 . The closer the $\mathrm{R}^{2}$ value to unity, the better the kinetic model fitted the experimental data. The $N$ value in the Fractional power model was less than unity which indicated time dependent of adsorption on Musa sapientum peels adsorbent [12]. The $\mathrm{R}^{2}$ value was approaching unity however it was not the best $\mathrm{R}^{2}$ among the models considered in this work hence Fractional power model was ignored. Lagergren pseudo first - order model, Blanchard kinetic model and Behnajady - Modirshahla - Ghanbery model were jettisoned as their $\mathrm{R}^{2}$ values were not close to unity.

Table 1 Kinetic model parameter and coefficient of determination values for treatment of leachate using Musa

\begin{tabular}{|c|c|c|c|}
\hline $\mathbf{S} / \mathbf{N}$ & Kinetic model & Parameters & Value \\
\hline \multirow[t]{3}{*}{1} & \multirow[t]{3}{*}{ Fractional power model } & $N$ & 0.214 \\
\hline & & $k_{F}$ & 5762.922 \\
\hline & & $\mathrm{R}^{2}$ & 0.9764 \\
\hline \multirow[t]{2}{*}{2} & \multirow[t]{2}{*}{ Lagergren pseudo first order model } & $K_{1}$ & 0.0572 \\
\hline & & $\mathrm{R}^{2}$ & 0.8719 \\
\hline \multirow[t]{2}{*}{3} & \multirow[t]{2}{*}{ Pseudo second - order kinetic model } & $K_{2}$ & 0.05581 \\
\hline & & $\mathrm{R}^{2}$ & 0.99996 \\
\hline \multirow[t]{3}{*}{4} & \multirow[t]{3}{*}{ Kuo - Lotse kinetic model } & $\alpha_{m F}$ & 4.6685 \\
\hline & & $k_{m F}$ & 15.7028 \\
\hline & & $\mathrm{R}^{2}$ & 0.9764 \\
\hline \multirow[t]{3}{*}{5} & \multirow[t]{3}{*}{ Blanchard kinetic model } & $\alpha_{B}$ & $4.838 \times 10^{-4}$ \\
\hline & & $k_{B}$ & $1.481 \times 10^{-5}$ \\
\hline & & $\mathrm{R}^{2}$ & 0.6734 \\
\hline \multirow[t]{3}{*}{6} & \multirow[t]{3}{*}{ Elovich kinetic model } & $\alpha$ & 4698.27 \\
\hline & & $\beta$ & 0.0003219 \\
\hline & & $\mathrm{R}^{2}$ & 0.9690 \\
\hline \multirow[t]{2}{*}{7} & \multirow[t]{2}{*}{ Sobkowsk - Czerwi kinetic model } & $k_{s c}$ & -359.712 \\
\hline & & $\mathrm{R}^{2}$ & 0.8541 \\
\hline \multirow[t]{2}{*}{8} & \multirow[t]{2}{*}{ IPD model } & $k_{I P D}$ & 690.5498 \\
\hline & & $\mathrm{R}^{2}$ & 0.9552 \\
\hline \multirow[t]{3}{*}{9} & \multirow[t]{3}{*}{ BMG model } & $b$ & 34.868 \\
\hline & & $m$ & -1477.607 \\
\hline & & $\mathrm{R}^{2}$ & 0.6730 \\
\hline \multirow[t]{2}{*}{10} & Diffusion - Chemisorption & $\mathrm{k}_{D C}$ & 3947.888 \\
\hline & & $\mathrm{R}^{2}$ & 0.9823 \\
\hline
\end{tabular}
sapientum peels as bio-sorbent 
Elovich kinetic model can be taken to fit kinetic experimental data provided the $\mathrm{R}^{2}$ value was greater than unity. In this work, the $\mathrm{R}^{2}$ value was 0.9690 which was less than unity hence the model was rejected. Sobkowsk - Czerwi kinetic model will fit kinetic data if the intercept on the vertical axis is unity but in this work, the intercept of the plot on vertical axis was 1.4623 and on this basis, it was ignored. IPD model can be used to identify the mechanism involved in the adsorption process system. Using the model, the plot must pass through the origin which was not in line with the plot obtained in this work and as a result, it was jettisoned. Pseudo second - order kinetic model, Kuo - Lotse kinetic model, and IPD model have their $\mathrm{R}^{2}$ values close to unity. However, Pseudo second - order kinetic model has the best $\mathrm{R}^{2}$ value of 0.99996 among these three models. On the basis of this, Pseudo second - order kinetic model was adopted as the best model that fitted the experimental data obtained in this work. Previous works of El - Nafatyet al. (2013)[3] and Deshmukh et al. (2017) [11] also revealed that using Musa sapientum peels as bio-sorbent in the removal of cadmium and oil respectively from aqueous solution followed Pseudo second order kinetic model.

\section{Conclusion}

The kinetic process of dumpsite leachate treatment using Musa sapientum peels as bio-sorbent has been modeled. The percentage removal of TDS increased as the contact time between the adsorbent and the leachate increased up to 150 mins after which there was no significant removal in the TDS. Various kinetic models were tested with the kinetic process data. Lagergren pseudo first - order, Blanchard kinetic model and BMG models were rejected as their R2 values were not close to unity. Elovich kinetic model was ignored because the R2 value was not greater than unity. IPD model was jettisoned as the plot did not pass through the origin. Fractional power model, Pseudo second - order kinetic model, Kuo - Lotse kinetic model and Diffusion - Chemisorption model have their R2 values very close to unity however Pseudo second - order kinetic model has the best value in term of coefficient of determination hence it was adopted in this work as the best kinetic model that fitted the kinetic data of treatment of Lagos dumpsite leachate using Musa sapientum peels as bio-sorbent.

\section{Compliance with ethical standards}

\section{Acknowledgments}

The authors appreciate the assistance of all the technologists in the analytical laboratory of Department of Chemical Engineering, Lagos State University, Epe, Lagos State, for their contributions during the experimental works.

\section{Disclosure of conflict of interest}

Authors have declared that there is no existence of competing interests.

\section{References}

[1] Bhattacharyy KG, Sharma J,Sharma A. Adsorption of Pb (11) from aqueous solution by Azadirachaindica (Neem) leaf powder. Journal of Hazardous Materials. 2004; 113 (1 - 3): 97 - 109.

[2] Saimaqm, Muhammad IB,Jamil M. Evaluation of banana peel for treatment of arsenic contaminated water. Proceedings of the 1st technical meeting of Muslim water researchers cooperation, Malaysia. 2008; 104 - 109.

[3] El - Nafaty UA, Mohammad IM,Abdulsalam S. Biosorption and kinetic studies on oil removal from produced water using banana peels. Civil and Environmental Research. 2013; 3(7): 125 - 136.

[4] Lim PE, Lim SP, Seng CE,Noor AM. Treatment of landfill leachate in sequencing batch reactor supplemented with activated rice husk as adsorbent. Chemical Engineering Journal. 2010; 159 (1 - 3): 123 - 128.

[5] Aziz SO, Aziz HA, Yusoff MS,bashir M. Landfill leachate treatment using powdered activated carbon augmented sequencing batch reactor (SBR) process: Optimization by response surface methodology. Journal of Hazardous Materials. 2011; 189 (1 - 2): $404-413$.

[6] Kalderis D, Koutoulakis D, Paraskeva P, Diamodopoulos E, Otal E, Del Valle JO,Fernandez - Pereira C. Adsorption of polluting substances on activated carbon prepared from rice husk and sugarcane bagasse. Chemical Engineering Journal. 2008; 144(1): 42 - 50.

[7] Liyan S, Youcai Z, Weimin S,Ziyang J. Hydrophobic organic chemicals removal from biologically treated landfill leachate by powdered activated carbon, granular activated carbon and bimimetic fat cell. Journal of Hazardous Materials. 2009; 163(2 - 3): $1084-1089$. 
[8] Ab Ghani Z, Yusoff MS, Zaman NQ, Zamir MFMA,Andas J. Optimization of preparation conditions for activated carbon from banana pseudo - stem using response surface methodology on removal of colour and COD from landfill leachate. Waste Management. 2014; 62: 177 - 187.

[9] Zajc NC, Glancer M,Gromping M Laboratory scale and pilot study of the treatment of municipal landfill leachate. Chemical and Biochemical Engineering Quarterly. 2004; 18(1): 77 - 84.

[10] Yahya MD, Mohammed - Dabo IA, Ahmed AS,Olawale AS. Adsorptive removal of lead from aqueous solution using raw and modified shea butter cake. Journal of the Nigerian Society of Chemical Engineers. 2017; 32 (1): 25 - 33.

[11] Deshmukh PD, Khadse GK, Shinde VM,Labhasetwar P. Cadmium removal from aqueous solution using dried banana peels as an adsorbent: kinetic and equilibrium modeling. Journal of Bioremediation and Biodegradation. 2017; 8(3): 1-7.

[12] Olafadehan OA, Akpo OY, Enemuo O, Amoo KO,Abatan OG. Equilibrum, kinetic and thermodynamic studies of biosorption of zinc ions from industrial wastewater using derived composite bio-sorbents from walnut shell. African Journal of Environmental Science and Technology. 2018; 12(9): 335 - 350.

[13] Sumanik NB, Nurvitasari E, Maarebia RZ,Langkong J. Decrease of lead levels of leachate with banana skin adsorbent. Earth and Environmental Science. 2019; 343: 1 - 6.

[14] Sivarajasekar N,Baskar R. Adsorptipon of basic red onto activated carbon derived from immature cotton seeds: isotherm studies and error analysis. Desalination and Water Treatment. 2014; 52 (40 - 42): 7743 - 7765.

[15] American Public Health Association (APHA). Standard methods for the examination od water and wastewater, Washington DC, USA, 2005.

[16] Olafadehan OA. Fundamentals of adsorption processes. LAP Lambert Academic Publishing, Mauritius. 2021. 